\title{
Heat Transfer on a Film-Cooled Rotating Blade Using a Two-Equation Turbulence Model
}

\author{
VIJAY K. GARG* \\ AYT Corporation, NASA Lewis Research Center, 21000 Brookpark Road, Mail Stop 5-11, Cleveland, OH 44135, USA \\ (Received 7 October 1997; In final form 28 October 1997)
}

\begin{abstract}
A three-dimensional Navier-Stokes code has been used to compare the heat transfer coefficient on a film-cooled, rotating turbine blade. The blade chosen is the ACE rotor with five rows containing 93 film cooling holes covering the entire span. This is the only filmcooled rotating blade over which experimental data is available for comparison. Over 2.278 million grid points are used to compute the flow over the blade including the tip clearance region, using Coakley's $q-\omega$ turbulence model. Results are also compared with those obtained by Garg and Abhari (1997) using the zero-equation Baldwin-Lomax (B-L) model. A reasonably good comparison with the experimental data is obtained on the suction surface for both the turbulence models. At the leading edge, the $B-L$ model yields a better comparison than the $q-\omega$ model. On the pressure surface, however, the comparison between the experimental data and the prediction from either turbulence model is poor. A potential reason for the discrepancy on the pressure surface could be the presence of unsteady effects due to stator-rotor interaction in the experiments which are not modeled in the present computations. Prediction using the two-equation model is in general poorer than that using the zero-equation model, while the former requires at least $\mathbf{4 0 \%}$ more computational resources.
\end{abstract}

Keywords: Film cooling, Turbine blade, Turbulence models

\section{INTRODUCTION}

Film cooling is one of the most efficient ways of protecting a turbine blade from the hot gas around it. However, the cooler air injected through the film-cooling holes in the blade is bled directly from the compressor before it passes through the combustion chamber. Thus, in order to minimize the use of coolant flow, turbine designers need to have an accurate prediction of the component heat load and film cooling effectiveness. While a considerable effort has been devoted to understanding the coolant film behavior and its interaction with the mainstream flow, many studies on film cooling have been confined to simple geometries, for example, two-dimensional flat and curved plates in steady, incompressible flow. An excellent survey of the work up to 1971 has been provided by

*Tel.: 216-433-6788. Fax: 216-433-5802. E-mail: vijay.garg@lerc.nasa.gov. 
Goldstein (1971). While several further studies in this field have been summarized by Garg and Gaugler (1993, 1994, 1996), some relevant ones are discussed here.

Three detailed experimental measurements of film cooling on rotating turbine blades are available (Dring et al., 1980; Abhari, 1991; Takeishi et al., 1991). All three studies concluded that film cooling on the suction surface provides good surface protection, while on the pressure surface the results are mixed. The measurement database of Abhari (1991), being the only experimental measurement of surface heat transfer for a filmcooled rotating transonic turbine blade, provides the experimental results for the present numerical study. Abhari and Epstein (1994) also showed that the unsteady rotor-stator interaction results in the pulsation of the flow out of the film cooling holes. This coolant pulsation was later shown by Abhari (1996) to result in a considerable reduction on the pressure surface film effectiveness while the suction surface was relatively unaffected.

Many different approaches to the prediction of film cooling performance have been developed over the years. One approach has been to model the penetration, spreading and entrainment of the main flow by the coolant jets from the discrete holes. These interaction models have been incorporated into boundary layer codes (Crawford et al., 1980; Schönung and Rodi, 1987; Tafti and Yavuzkurt, 1990) or into two dimensional Navier-Stokes code (Abhari, 1996). In another approach, Garg and Gaugler (1993, 1994, 1996, 1997a,b) used a three dimensional Navier-Stokes code with surface injection to model the film cooling performance around the $\mathrm{C} 3 \mathrm{X}$ vane, and the VKI and ACE rotor cascades, while Garg (1997), and Garg and Abhari (1997) analyzed film-cooled rotating blades, specifically the UTRC rotor and the ACE rotor. In this approach, similar to the present technique, the film holes are modeled by adding, as a boundary condition, the appropriate amount of mass, momentum, and energy flux distribution at the discrete location of the film holes. They compared the predictions to the experimental measurements on these cascades and rotating blades, and found a fairly good agreement using the $\mathrm{B}-\mathrm{L}$ model. The computational results clearly illustrated the three dimensionality of the flow in the near hole region. Choi (1993) also used a three-dimensional code to predict the flow and the surface heat transfer around a section of the ACE turbine blade. The computational grid was extended into the film holes to model the elliptic nature of the flow at the film hole exit plane. In order to minimize the size of the computational grid and the associated computational resource requirements, Choi only modeled a section of the blade which in the span-wise direction covered one half of a film hole pitch with span-wise periodic boundary conditions. Such a reduction in computational span is possible, however, for a linear cascade only, and was also used by Garg and Gaugler (1993, 1994, 1996, 1997a,b). For a rotating blade, the entire span needs to be discretized in order to model correctly the rotational body forces.

The goal of the present study is to provide an insight into the turbulence modeling issues for film cooling of a transonic turbine rotor with rotation. The approach is to numerically model the experimental conditions of a measurement study by Abhari (1991) using the ACE turbine blade. A number of operating conditions with film cooling were simulated using the $q-\omega$ turbulence model, and the predicted results compared to the experimental data and earlier computations using the B-L model. These comparisons combined with observations from the surface heat loads on the blade are used to evaluate the $q-\omega$ model for the film cooling of rotor blades and make observations on the influence of turbulence modeling in such a situation.

\section{ANALYSIS}

The three-dimensional Navier-Stokes code of Arnone (1994) for the analysis of turbomachinery flows was modified by Garg and Gaugler (1994) to include film cooling effects. Briefly, the code is an explicit, multigrid, cell-centered, finite volume code with an algebraic turbulence model. The 
Navier-Stokes equations in a rotating Cartesian coordinate system are mapped onto a general bodyfitted $(\xi, \eta, \zeta)$ coordinate system using standard techniques. The governing equations, dropping all viscous derivatives in the $\xi$-direction following the thin-layer approximation (see Garg and Gaugler, 1994 for justification), are:

$\partial_{t} q+J\left[\partial_{\xi} E+\partial_{\eta} F+\partial_{\zeta} G-R e^{-1}\left(\partial_{\eta} F_{v}+\partial_{\zeta} G_{v}\right)\right]=H$,

where

$q=\left[\begin{array}{c}\rho \\ \rho u \\ \rho v \\ \rho w \\ e\end{array}\right], \quad E=J^{-1}\left[\begin{array}{c}\rho U^{\prime} \\ \rho u U^{\prime}+\xi_{x} p \\ \rho v U^{\prime}+\xi_{y} p \\ \rho w U^{\prime}+\xi_{z} p \\ e U^{\prime}+p U\end{array}\right]$,
$F=J^{-1}\left[\begin{array}{c}\rho V^{\prime} \\ \rho u V^{\prime}+\eta_{x} p \\ \rho v V^{\prime}+\eta_{y} p \\ \rho w V^{\prime}+\eta_{z} p \\ e V^{\prime}+p V\end{array}\right], \quad G=J^{-1}\left[\begin{array}{c}\rho W^{\prime} \\ \rho u W^{\prime}+\zeta_{x} p \\ \rho v W^{\prime}+\zeta_{y} p \\ \rho w W^{\prime}+\zeta_{z} p \\ e W^{\prime}+p W\end{array}\right]$,

$F_{v}=J^{-1} \mu\left[\begin{array}{lllll}0 & F_{2} & F_{3} & F_{4} & F_{5}\end{array}\right]^{\mathrm{T}}$,

$G_{v}=J^{-1} \mu\left[\begin{array}{lllll}0 & G_{2} & G_{3} & G_{4} & G_{5}\end{array}\right]^{\mathrm{T}}$,

$H=\Omega\left[\begin{array}{lllll}0 & 0 & -\rho w & \rho v & 0\end{array}\right]^{\mathrm{T}}$,

with

$$
\begin{aligned}
F_{2}= & C_{1} \partial_{\eta} u+C_{2} \eta_{x}+C_{3} \partial_{\zeta} u-C_{4} \eta_{x}+C_{5} \zeta_{x}, \\
F_{3}= & C_{1} \partial_{\eta} v+C_{2} \eta_{y}+C_{3} \partial_{\zeta} v-C_{4} \eta_{y}+C_{5} \zeta_{y}, \\
F_{4}= & C_{1} \partial_{\eta} w+C_{2} \eta_{z}+C_{3} \partial_{\zeta} w-C_{4} \eta_{z}+C_{5} \zeta_{z}, \\
F_{5}= & \frac{\mu \gamma}{P r}\left[C_{1} \partial_{\eta}\left(C_{v} T\right)+C_{3} \partial_{\zeta}\left(C_{v} T\right)\right] \\
& +u F_{2}+v F_{3}+w F_{4},
\end{aligned}
$$

and

$$
\begin{aligned}
& C_{1}=\eta_{x}^{2}+\eta_{y}^{2}+\eta_{z}^{2}, \\
& C_{2}=\frac{1}{3}\left(\eta_{x} \partial_{\eta} u+\eta_{y} \partial_{\eta} v+\eta_{z} \partial_{\eta} w\right), \\
& C_{3}=\eta_{x} \zeta_{x}+\eta_{y} \zeta_{y}+\eta_{z} \zeta_{z}, \\
& C_{4}=\frac{2}{3}\left(\zeta_{x} \partial_{\zeta} u+\zeta_{y} \partial_{\zeta} v+\zeta_{z} \partial_{\zeta} w\right), \\
& C_{5}=\eta_{x} \partial_{\zeta} u+\eta_{y} \partial_{\zeta} v+\eta_{z} \partial_{\zeta} w .
\end{aligned}
$$

Terms multiplied by $C_{1}$ and $C_{2}$ lead to non-mixed second derivative viscous terms like $u_{\zeta \zeta}$, while terms multiplied by $C_{3}, C_{4}$ and $C_{5}$ lead to mixed derivative terms like $u_{\eta \zeta}$. Terms for the viscous flux vector $G_{v}$ can be written similarly by interchanging $\eta$ and $\zeta$, and replacing $F$ by $G$ everywhere in Eqs. (3) and (4).

The solution is obtained in terms of the absolute velocity components $(u, v, w)$ in the Cartesian coordinate system $(x, y, z)$ attached to the moving blade, while $(U, V, W)$ are the contravariant and $\left(U^{\prime}, V^{\prime}, W^{\prime}\right)$ are the relative contravariant velocity components defined as

$$
\begin{array}{ll}
U=\xi_{x} u+\xi_{y} v+\xi_{z} w, & U^{\prime}=\xi_{x} u^{\prime}+\xi_{y} v^{\prime}+\xi_{z} w^{\prime}, \\
V=\eta_{x} u+\eta_{y} v+\eta_{z} w, & V^{\prime}=\eta_{x} u^{\prime}+\eta_{y} v^{\prime}+\eta_{z} w^{\prime}, \\
W=\zeta_{x} u+\zeta_{y} v+\zeta_{z} w, & W^{\prime}=\zeta_{x} u^{\prime}+\zeta_{y} v^{\prime}+\zeta_{z} w^{\prime},
\end{array}
$$

where

$$
u^{\prime}=u, \quad v^{\prime}=v-\Omega z, \quad w^{\prime}=w+\Omega y,
$$

are the relative velocity components in the Cartesian system and $\Omega$ is the rotational speed. The energy and static pressure are given by

$$
\begin{aligned}
& e=\rho\left[C_{v} T+\frac{1}{2}\left(u^{2}+v^{2}+w^{2}\right)\right], \\
& p=(\gamma-1)\left[e-\frac{1}{2} \rho\left(u^{2}+v^{2}+w^{2}\right)\right] .
\end{aligned}
$$

Metric terms are defined by

$$
\begin{aligned}
& {\left[\begin{array}{lll}
\xi_{x} & \eta_{x} & \zeta_{x} \\
\xi_{y} & \eta_{y} & \zeta_{y} \\
\xi_{z} & \eta_{z} & \zeta_{z}
\end{array}\right]} \\
& \quad=J\left[\begin{array}{lll}
y_{\eta} z_{\zeta}-y_{\zeta} z_{\eta} & y_{\zeta} z_{\xi}-y_{\xi} z_{\zeta} & y_{\xi} z_{\eta}-y_{\eta} z_{\xi} \\
x_{\zeta} z_{\eta}-x_{\eta} z_{\zeta} & x_{\xi} z_{\zeta}-x_{\zeta} z_{\xi} & x_{\eta} z_{\xi}-x_{\xi} z_{\eta} \\
x_{\eta} y_{\zeta}-x_{\zeta} y_{\eta} & x_{\zeta} y_{\xi}-x_{\xi} y_{\zeta} & x_{\xi} y_{\eta}-x_{\eta} y_{\xi}
\end{array}\right],
\end{aligned}
$$

where the Jacobian is given by

$$
\begin{aligned}
J=( & x_{\xi} y_{\eta} z_{\zeta}+x_{\zeta} y_{\xi} z_{\eta}+x_{\eta} y_{\zeta} z_{\xi}-x_{\xi} y_{\zeta} z_{\eta} \\
& \left.-x_{\eta} y_{\xi} z_{\zeta}-x_{\zeta} y_{\eta} z_{\xi}\right)^{-1} .
\end{aligned}
$$

The equations are non-dimensionalized by the inlet total density $\rho_{0}$, the blade axial chord as the 
characteristic length, and $\left(R T_{0}\right)^{1 / 2}$ as the characteristic velocity. It is assumed that the effective viscosity for turbulent flows can be written as

$$
\mu_{\mathrm{ef}}=\mu_{\ell}+\mu_{\mathrm{T}},
$$

where the laminar viscosity $\mu_{\ell}$ is calculated using Sutherland's law (Schlichting, 1979). The turbulent viscosity $\mu_{\mathrm{T}}$ is computed using a two-equation model as described below.

The multistage Runge-Kutta scheme developed by Jameson et al. (1981) is used to advance the flow solution in time from an initial guess to the steady state. To accelerate convergence the code employs the Full Approximation Storage (FAS) multigrid method originally devised by Brandt (1979) and Jameson (1983). Variable coefficient implicit smoothing of the residuals is performed to improve further the rate of convergence. A three-dimensional extension of eigenvalue scaling of the artificial dissipation terms, first devised by Martinelli (1987), was adopted to prevent odd-even decoupling and to capture shocks. A spatially varying time step along with a Courant-Friedrichs-Levy (CFL) number of 4 was used to speed convergence to the steady state.

\section{Turbulence Model}

Turbulence was modeled using a low-Reynolds number two-equation model. Transition to turbulence is automatically mimicked by such a model. Owing to its robustness, Coakley's $q-\omega$ model was selected for comparison with the experimental data, and with the algebraic mixing length turbulence model of Baldwin and Lomax (1978). The general formulation for the two-equation model can be written as

$$
\begin{aligned}
& \left(\rho s_{i}\right)_{, t}+\left(\rho s_{i} u_{j}+q_{i j}\right)_{, j}=H_{i}, \\
& q_{i j}=-\left(\mu+\mu_{\mathrm{T}} / P r_{i}\right) s_{i, j}, \quad i=1,2 .
\end{aligned}
$$

For Coakley's $q-\omega$ model (Coakley, 1983), the variables $s_{1}$ and $s_{2}$ are

$$
s_{1}=q, \quad s_{2}=\omega, \quad \mu_{\mathrm{T}}=C_{\mu} D \rho q^{2} / \omega .
$$

The source terms in the model equations are

$$
\begin{aligned}
& H_{q}=\frac{1}{2}\left[C_{\mu} D S / \omega-\frac{2}{3} \Im-\omega\right] \rho q, \\
& H_{\omega}=\left[C_{1}\left(C_{\mu} S / \omega-\frac{2}{3} \Im\right)-C_{2} \omega\right] \rho \omega .
\end{aligned}
$$

The strain rate invariant $S$, and the divergence of the velocity $\Im$, appearing in Eqs. (13) are

$$
S=\left(u_{i, j}+u_{j, i}-\frac{2}{3} \delta_{i j} u_{k, k}\right) u_{i, j}, \quad \Im=u_{k, k}
$$

Following Menter (1993), however, it was found that taking $S$ to be the square of vorticity yielded better convergence characteristics and surface heat transfer results. $D$ is a damping function defined as

$$
D=1-\exp (-\alpha R), \quad R=q y / \nu
$$

and

$$
\begin{gathered}
\operatorname{Pr}_{q}=1.0, \quad \operatorname{Pr}_{\omega}=1.3, \quad C_{\mu}=0.09, \\
C_{1}=0.405 D+0.045, \quad C_{2}=0.92, \quad \alpha=0.0065 .
\end{gathered}
$$

The turbulence model equations were incorporated into the code and solved explicitly along with the flow equations, following Ameri and Arnone (1992, 1994). No fourth order dissipation terms were needed for the turbulence model equations. Variable coefficient implicit residual smoothing was adapted to the model equations as well by setting up the coefficients using the eigenvalues of the model equations. This along with proper linearization of the source terms in the model equations and implicit solution for $q$ and $\omega$ allowed the use of $\mathrm{CFL}=2$ for the turbulence model equations while $\mathrm{CFL}=4$ for the flow equations.

\section{Boundary Conditions}

At the inflow boundary, the total temperature, total pressure, whirl, and meridional flow angle are specified, and the upstream-running Riemann invariant based on the total absolute velocity is calculated at the first interior point and extrapolated to the inlet. The velocity components are then decoupled algebraically, and the density is found 
from total temperature, total pressure and total velocity using an isentropic relation. For the turbulence model, the value of $q$ and $\omega$ is specified using the experimental conditions, namely

$$
q=\sqrt{1.5} u_{\text {in }} T u_{\text {in }}, \quad \omega=q / l,
$$

where $T u_{\text {in }}$ is the intensity of turbulence at the inlet (taken to be 0.15 as the NGVs precede the rotor), $u_{\text {in }}$ is the inlet velocity, and $l$ is the turbulence length scale representing the size of the energy containing eddies. This length scale is usually not reported as part of the experimental conditions, and needs to be assumed. For the present study, $l$ was assumed to be $5 \%$ of the blade axial chord. Garg and Ameri (1997) report that using Chien's $k-\varepsilon$ model and changing $l$ to 0.01 or 0.25 for the $\mathrm{C} 3 \mathrm{X}$ vane resulted in negligible difference in the heat transfer coefficient at the blade surface as compared to that for $l=0.05$. It is reasonable to assume that similar results would hold for the ACE rotor using the $q-\omega$ model.

At the exit, the hub static pressure is specified and the density and velocity components are extrapolated from the interior. The local static pressure is found by integrating the axisymmetric radial equilibrium equation. Periodic flow conditions in terms of cylindrical velocity components are set on a dummy grid line outside the boundary. At the solid surfaces (the hub, the shroud and the rotating blade), the no-slip condition is enforced. The boundary conditions for turbulence quantities on the walls are $q=0$, and $\partial \omega / \partial n=0$.

The experimental values for the blade temperature were known at only 25 points on the blade surface, while the computational grid had over 38,000 grid points on the blade surface. Thus, in the absence of a complete surface temperature map, the blade surface was considered isothermal. The largest experimental variations in the blade surface temperature relative to the mean were as much as $12-20 \%$ of the temperature difference, $T_{\text {o,rel }}-T_{\mathrm{w}}$, used to compute the Nusselt number. The hub and shroud surfaces were also considered isothermal and assumed to be at the same temperature as the blade. Based upon an estimate obtained from a streamline curvature prediction, the boundary layer thickness on the hub and shroud was taken to be $10 \%$ and $15 \%$ of span, respectively, for the incoming flow to the rotor. The vena contracta of each hole was accounted for by reducing the actual hole exit area by the values of the estimated discharge coefficient, $C_{\mathrm{D}}$, reported in the Table I.

The effects of film cooling have been incorporated into the code in the form of appropriate boundary conditions at the hole locations on the blade surface. Each hole exit is represented by several control volumes having a total area equal to the area of the hole exit, and passing the same coolant mass flow, with the discharge coefficient for the hole having been taken into account. Different velocity and temperature profiles for the injected gas can be specified at the hole exit. For the cases reported here, uniform distribution of the coolant velocity (relative to the blade), temperature, turbulence intensity and length scale at the hole exit was specified. We may point out that using the BaldwinLomax model, Garg and Abhari (1997) report that a polynomial distribution of coolant velocity and temperature at the exit of the double-row of holes on the pressure surface did not produce any appreciable difference in the Nusselt number values on the pressure surface. Turbulence intensity at the hole exit was assumed to be 0.12 , while the turbulence length scale at the hole exit was taken to be $0.1 d$ in the absence of any experimental data for these quantities. It was found, however, that changing $T u$ to 0.06 and/or $l$ to $0.5 d$ at the hole exit resulted in a negligible change in the heat transfer coefficient at the blade surface, except in the immediate vicinity of the holes.

\section{ACE ROTOR AND EXPERIMENTAL DETAILS}

The Rolls-Royce ACE high pressure transonic turbine model was the test object on which film cooling data were taken in the short duration $(0.3 \mathrm{~s}$ measurement time), blowdown, rotating turbine rig facility at M.I.T. by Abhari (1991). In this facility, 
TABLE I Parameter values

Main flow parameters: $R=125.1 \mathrm{~J} / \mathrm{kg}-\mathrm{K}$

\begin{tabular}{lcccccc}
\hline Case & $p_{0}(\mathrm{kPa})$ & $T_{\mathrm{o}}(\mathrm{K})$ & $p_{\text {ex }}(\mathrm{kPa})$ & $\Omega(\mathrm{rpm})$ & $T_{\mathrm{w}}(\mathrm{K})$ & $\gamma$ \\
\hline 71 & 450.0 & 486.0 & 117.537 & 7087 & 321.3 & 1.246 \\
72 & 460.0 & 490.0 & 128.683 & 5610 & 325.0 & 1.255 \\
73 & 351.0 & 417.0 & 92.206 & 6330 & 310.0 & 1.276 \\
\hline
\end{tabular}

Coolant flow parameters: $R_{\mathrm{c}}=158.5 \mathrm{~J} / \mathrm{kg}-\mathrm{K}$

\begin{tabular}{lccccc}
\hline \multicolumn{6}{c}{ Coolant flow parameters: $R_{\mathrm{c}}=158.5 \mathrm{~J} / \mathrm{kg}-\mathrm{K}$} \\
\hline Case & $\gamma_{\mathrm{c}}$ & $T_{\text {o,rel }}(\mathrm{K})$ & \multicolumn{3}{c}{$p_{\text {o,rel }}(\mathrm{kPa})$} \\
\cline { 3 - 6 } & & & Hub & Mid-span & Tip \\
\hline 71 & 1.406 & 222.5 & 241.761 & 255.238 & 262.229 \\
72 & 1.405 & 224.5 & 258.683 & 268.410 & 275.503 \\
73 & 1.406 & 222.9 & 194.645 & 204.373 & 212.276 \\
\hline
\end{tabular}

Hole Characteristics: Hole diameter $=0.5 \mathrm{~mm}$, spanwise pitch $=2 \mathrm{~mm}$, spanwise angle $=90^{\circ}$

\begin{tabular}{|c|c|c|c|c|c|c|c|c|c|c|c|c|}
\hline \multirow[t]{3}{*}{ Hole-row } & \multicolumn{9}{|c|}{ Estimated discharge coefficient, $C_{\mathrm{D}}$} & \multirow{3}{*}{$\begin{array}{c}\text { Stream-wise angle } \\
\text { (deg) }\end{array}$} & \multirow[t]{3}{*}{ Hole-shape } & \multirow[t]{3}{*}{ \# of holes } \\
\hline & \multicolumn{3}{|c|}{ Hub for case } & \multicolumn{3}{|c|}{ Mid-span for case } & \multicolumn{3}{|c|}{ Tip for case } & & & \\
\hline & 71 & 72 & 73 & 71 & 72 & 73 & 71 & 72 & 73 & & & \\
\hline PS1 & 0.52 & 0.63 & 0.57 & 0.64 & 0.66 & 0.64 & 0.63 & 0.67 & 0.66 & 60 & Cylinder & 18 \\
\hline PS21 & 0.50 & 0.63 & 0.62 & 0.62 & 0.64 & 0.64 & 0.60 & 0.65 & 0.65 & 30 & Cylinder & 19 \\
\hline PS22 & 0.56 & 0.63 & 0.61 & 0.62 & 0.64 & 0.63 & 0.64 & 0.65 & 0.64 & 30 & Cylinder & 18 \\
\hline SS1 & 0.52 & 0.37 & 0.52 & 0.59 & 0.45 & 0.56 & 0.62 & 0.56 & 0.61 & 30 & D-shape & 18 \\
\hline $\mathrm{SS} 2$ & 0.48 & 0.48 & 0.48 & 0.39 & 0.39 & 0.39 & 0.46 & 0.46 & 0.46 & 30 & Cylinder & 20 \\
\hline
\end{tabular}

it is possible to simulate full engine scale Reynolds number, Mach number, Prandtl number, gas to wall and coolant to mainstream temperature ratios, specific heat ratios, and flow geometry while operating under benign operating conditions. A mixture of argon and freon-12 was used for the main flow while a mixture of argon and freon-14 was used as the coolant in order to prevent condensation at the low temperatures and high pressures of the coolant supply system. Values of the gas constant and specific heat ratios for the mainstream and coolant flows are given in Table I.

The ACE turbine geometry and cooling arrangement are shown schematically in Fig. 1. This turbine had a $551.2 \mathrm{~mm}$ rotor diameter with 36 nozzle guide vanes (NGVs) and 61 rotor blades. The rotor blades had an axial chord of $26.1 \mathrm{~mm}$, and five film cooling rows containing 93 holes. For the cooled rotor tests, thin walled NGVs were used with slot injection near the pressure surface trailing edge sized to pass the flow of a fully cooled NGV. Three instrumented and six other solid aluminum rotor blades were drilled out for two radially positioned coolant supply plenums; the other 52 rotor blades were of steel shell construction. The coolant film hole internal diameter was $0.5 \mathrm{~mm}$, and length to diameter ratio was large $(>20)$ for all holes. All rows had circular exit areas except for the first row (SS1) on the suction surface which was Dshaped. The cooling configuration consisted of: (a) one $30^{\circ}$ single row (SS1) of 18 D-shaped holes (fanned at $25^{\circ}$ half angle in the spanwise direction with an exit width of $1.25 \mathrm{~mm}$ ) at about $20 \%$ surface length on the suction surface, (b) one $30^{\circ}$ single row (SS2) of 20 round holes at about $70 \%$ surface length on the suction surface, (c) one $60^{\circ}$ 
single row (PS1) of 18 holes at about $25 \%$ surface length on the pressure surface, and (d) one $30^{\circ}$ double row of 19 (PS21) and 18 (PS22) staggered holes, with a chordwise spacing of $2 \mathrm{~mm}$, at about $50 \%$ surface length on the pressure surface. All holes were drilled at $90^{\circ}$ from the radial direction.

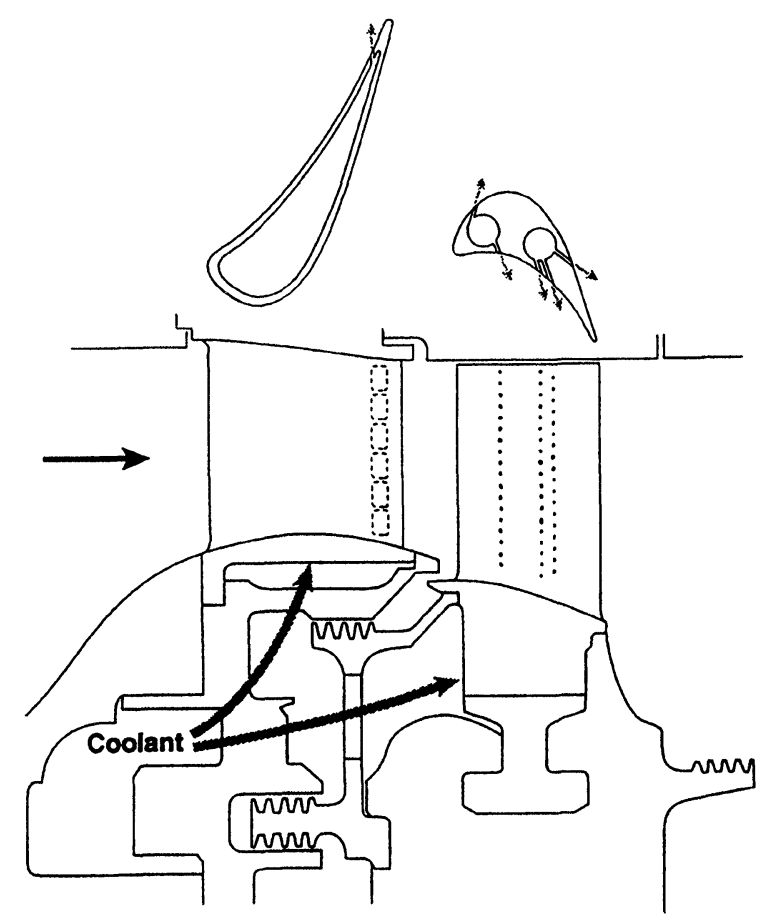

FIGURE 1 ACE turbine geometry and cooling arrangement.
More details in terms of estimated discharge coefficient for the holes are available in Table I. Figure 2 shows a small portion of the unfolded part of the blade containing the holes. The ordinate in Fig. 2 denotes the distance along the blade surface in the spanwise direction, while the abscissa denotes the distance, measured from the leading edge, along the blade surface in the streamwise direction, both normalized by the hole diameter, $d$. The shape and orientation of the hole openings in Fig. 2 is a direct consequence of the angles the holes make with the streamwise direction.

The heat flux from the free-stream to the blade was measured with thin film heat flux gauges distributed about the blade profile. These transducers are $25 \mu \mathrm{m}$ thick with a rectangular sensing area $(1.0 \times 1.3 \mathrm{~mm})$, oriented such that the longest dimension is in the chordwise direction. The coolant hole and heat flux gauge locations are shown in Fig. 3. The top chordwise row will be referred to as the tip location, the middle as mid-span, and the bottom as the hub gauges. Note that none of the three rows of gauges is at a fixed radial location. Unfortunately, several of the gauges failed over the course of the testing, especially on the pressure surface. Thus, not all measurement locations yielded data at all test conditions. High frequency response pressure transducers and thermocouples were installed in the NGVs and rotor blades to monitor the conditions in the coolant hole supply plenums. Facility measurements included inlet total temperature and pressure, outlet total pressure,

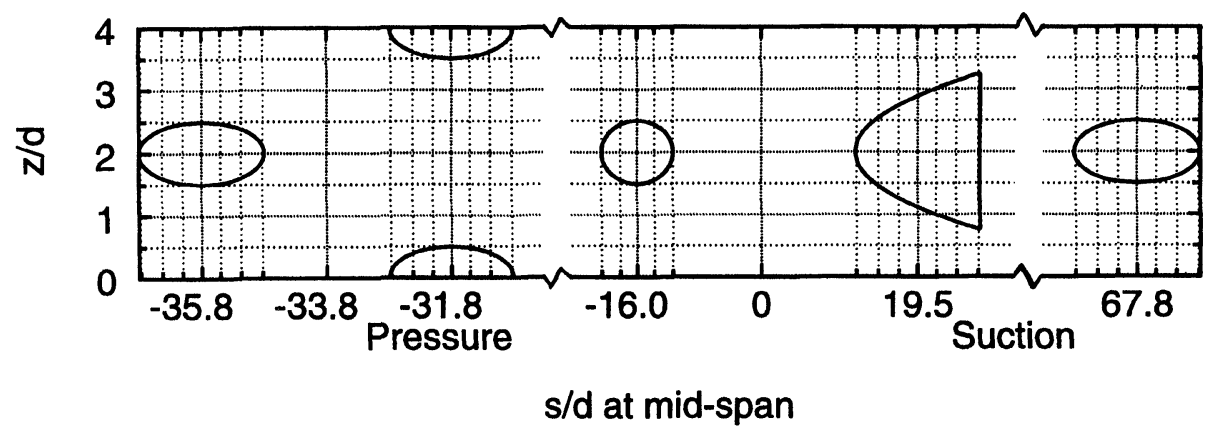

FIGURE 2 Shape of film cooling holes at exit on the ACE rotor surface. 


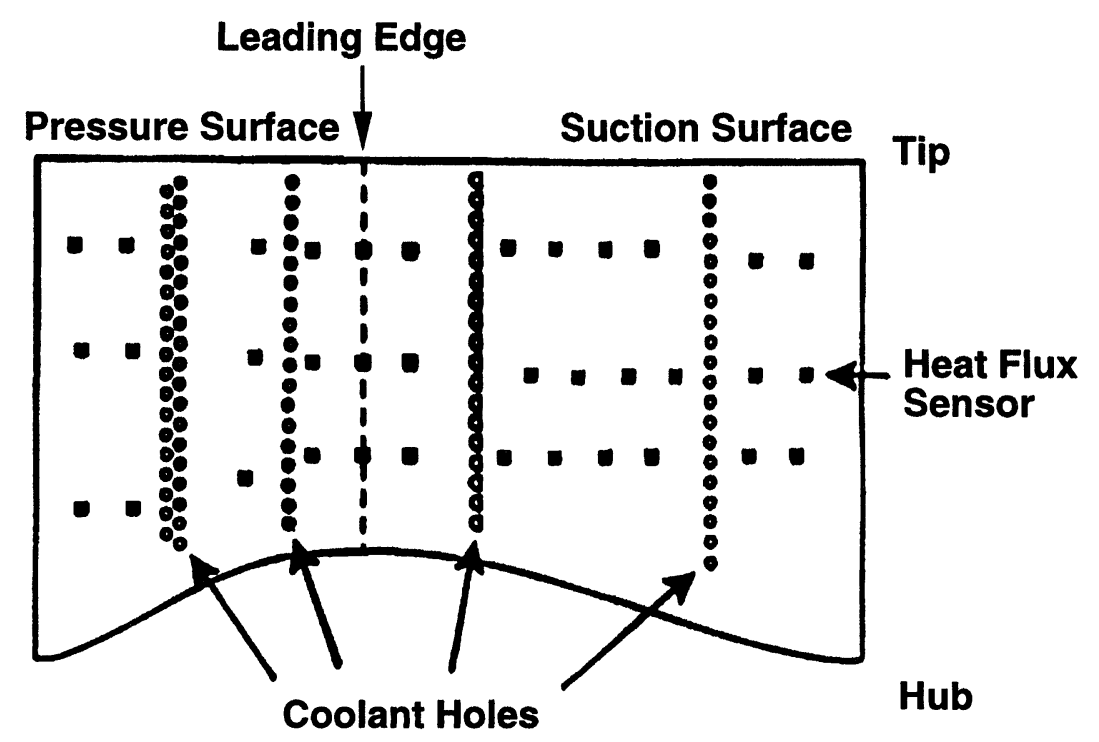

FIGURE 3 Heat flux gauges and cooling hole locations on the projected blade surface with each of the three chordwise rows of gauges on a separate blade.

wall static pressures, and rotor speed. More details are available in Abhari (1991).

\section{COMPUTATIONAL DETAILS}

The grid size is non-uniform in all directions so as to pack more grid points within the hole-exits and near the boundary layers on the blade, the hub and the shroud. For computational accuracy, the ratio of two adjacent grid sizes in any direction was kept within 0.76-1.3. A periodic C-grid with over $2,278,000$ grid points was used. The grid used was $225 \times 45 \times 225$ where the first number represents the number of grid points along the wrap-around direction for the $\mathrm{C}$-grid, the second in the blade-toblade direction, and the third in the span direction. This grid was arrived at following numerical experimentation with a coarser grid $133 \times 41 \times 113$ that yielded Nusselt number values at the blade surface about $10 \%$ different from those presented here. Normal to the blade surface is the dense viscous grid, with $y^{+}<1.0$ for the first point off the blade surface, following Boyle and Giel (1992), and Hall et al. (1994). Normal to the hub and shroud also is a dense grid, with $z^{+}<2.5$ for the first point off the hub or off the shroud. Also, the tip clearance region was taken to be $1 \%$ of the blade span (static measurement) with 20 grid points within it. The tip clearance region is handled by imposing periodicity conditions across the airfoil. Figure 4 shows the grid on the rotor surface with suction surface in the front, and the C-grid on the hub. Only alternate grid lines are shown in this figure for the sake of clarity. Also, extension of the $\mathrm{C}$-grid all the way to the shroud is not shown to avoid confusion. The location of the rows of holes is indicated by arrows. Computations were run on the 16-processor C90 supercomputer at the NASA Ames Research Center. For the two-equation turbulence model, the code requires about 182 million words $(\mathrm{Mw})$ of storage and takes about $58 \mathrm{~s}$ per iteration (fullmultigrid) on the $\mathrm{C} 90$ machine. For a given grid the first isothermal blade case requires about 1000 iterations to converge, while subsequent cases (corresponding to different values of the parameters) for the same grid require about 500 iterations starting with the solution for the previous case. While the iteration for solution proceeds through conservation of mass, momentum and energy for each control volume, the heat transfer coefficient at the blade surface was found to converge when the 


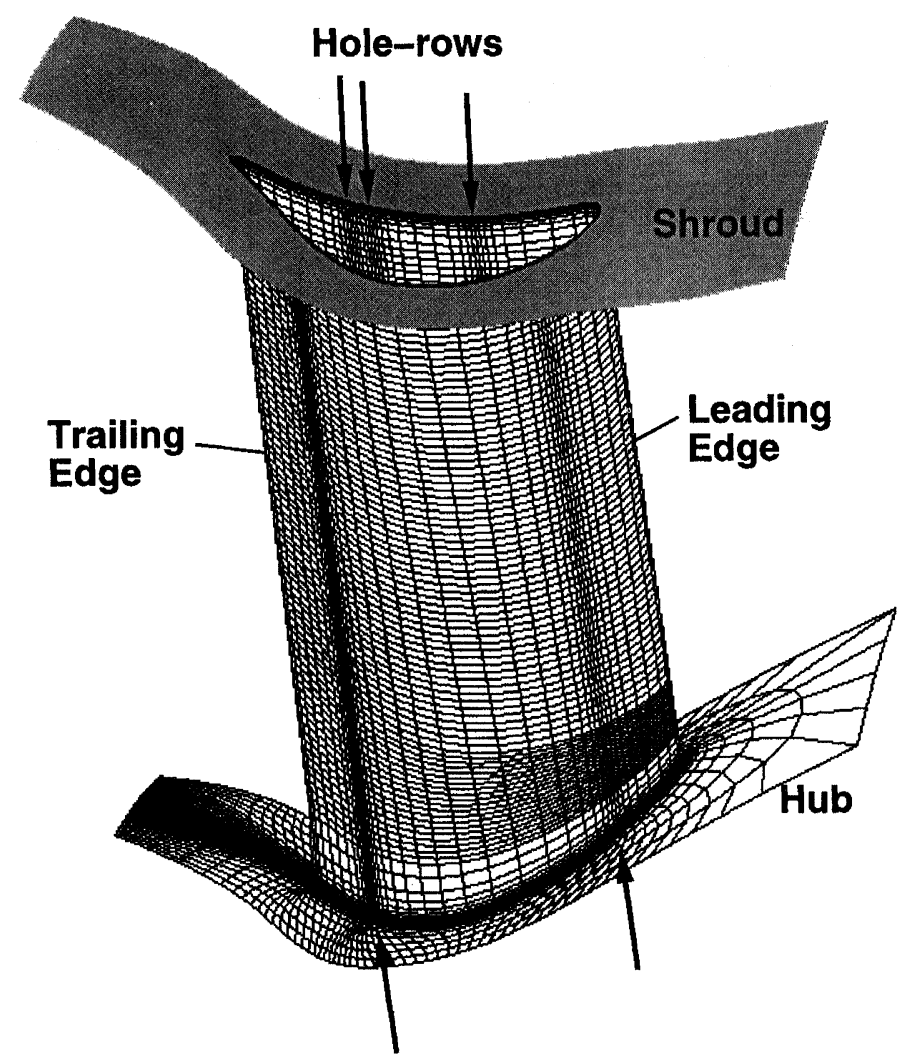

FIGURE 4 Grid on the blade surface, and C-grid on the hub. Suction surface is in the front. Alternate grid lines shown.

overall mass balance between the inlet and exit of the blade row was within $0.5 \%$.

\section{RESULTS AND DISCUSSION}

The present numerical results were obtained by simulating the exact experimental conditions of the MIT experiment given in Table I for the cases compared. The blowing parameter, $B_{\mathrm{p}}$, and the coolant temperature, $T_{\mathrm{c}} / T_{\mathrm{o}}$, at the hole exits were estimated from the static pressure distribution on an uncooled blade (found by executing the present code in the uncooled mode), and the relative total pressure and temperature measured in the coolant plenums, with coolant Mach number, relative to the rotor, restricted to unity at the hole-exit, assuming one-dimensional compressible flow through the hole-pipe. All holes in the second row (SS2) and most holes in the first row (SS1), especially those near the hub, on the suction surface were choked. Three film-cooled cases, Run \#71, 72 and 73, were selected for comparison, as detailed in Table I. While case \#71 represents near design-condition operation, test case \#73 represents a lower pressure ratio and speed, and case $\# 72$ has a positive incidence angle. Figure 5 shows the variation of (isentropic) relative Mach number on the blade surface for the three cases. While there is a little difference for cases \#71 and 73, the effect of a positive incidence angle for case \#72 is clearly visible on the suction surface. Except at the leading edge, the sudden changes in $M_{\text {rel }}$ values occur at the locations of the film-cooling holes.

Figure 6 compares the predicted Nusselt number on the blade surface near the hub, mid-span and tip, computed using the $q-\omega$ or Baldwin-Lomax model, with the experimental data for the film-cooled 


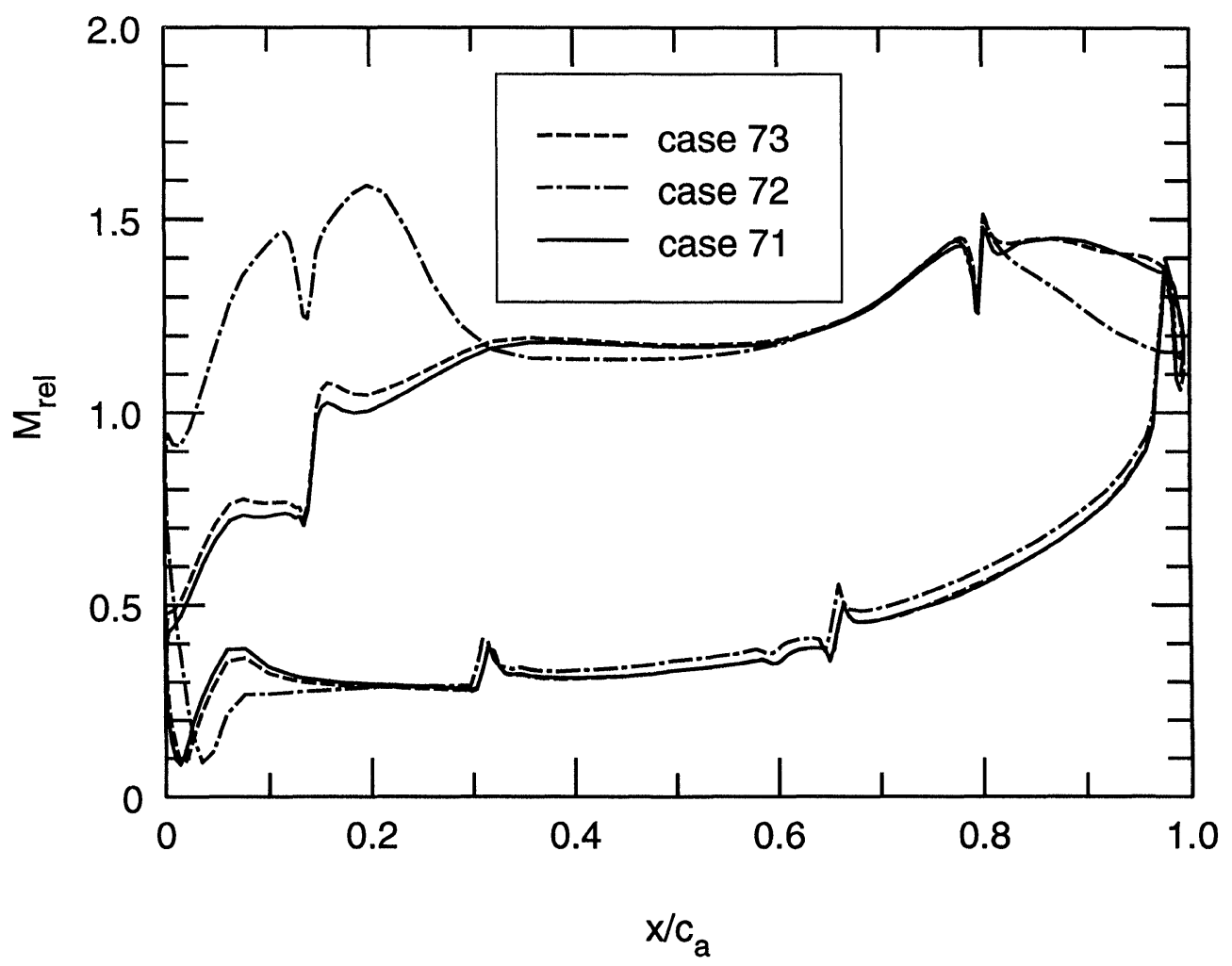

FIGURE 5 Relative Mach number on the blade surface for various cases.

baseline case \#71. The Nusselt number is based on the rotor axial chord, the relative total temperature at entry to the rotor, the blade temperature, and the gas thermal conductivity at the blade temperature. The abscissa is the fractional wetted pressure and suction surface of the blade. The five short vertical lines in this figure and in Figs. 7 and 8 denote the location of film cooling rows. The experimental data are shown with error bars. Presence of negative values of $N u$ at some locations simply implies that the direction of heat transfer is reversed at these locations due to specification of the isothermal wall boundary condition and coolant temperature. The comparison is very good at the leading edge for the B-L model, generally good on the suction surface for both turbulence models but fairly poor downstream of PS1 on the pressure surface near the hub. It is interesting to note that near the hub section, where the best experimental data coverage is available, the suction surface heat transfer is very well predicted by both the models in terms of the level and the distribution of surface heat flux. On the pressure surface, however, both models underpredict the heat transfer, and the $q-\omega$ model under-predicts it more than the B-L model. This comparison suggests that, in the presence of film cooling, both turbulence models correctly simulate the driving mechanisms for heat transfer on the suction surface. Reasons for the under-prediction on the pressure surface are cited later.

In Figs. 7 and 8, similar comparisons of numerical prediction of Nusselt number with the experimental data for film-cooled cases \#72 and \#73 are shown, respectively. It may be noted that Garg and Abhari (1997) found similar under-prediction on the pressure surface and good comparison with experimental data on the suction surface for an uncooled case while using the $\mathrm{B}-\mathrm{L}$ model. There are 

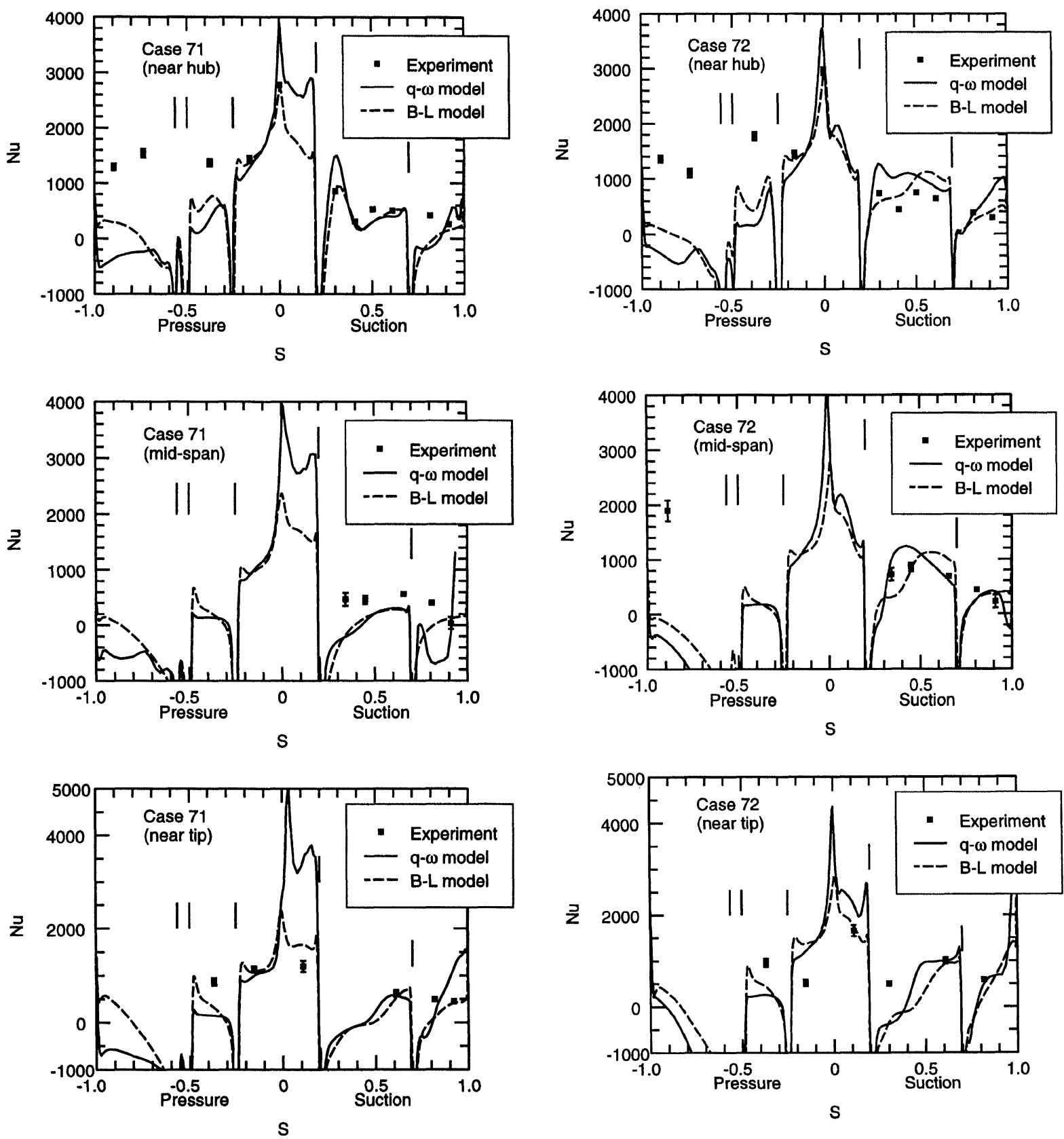

FIGURE 6 Comparison of Nusselt number on the blade surface for case 71 near hub, mid-span and tip based on two turbulence models (near design-condition operation).

a number of possible reasons for the poor comparison with the experimental data on the pressure surface. There is a strong evidence (Abhari, 1996) that the periodic flow unsteadiness resulting from

FIGURE 7 Comparison of Nusselt number on the blade surface for case 72 near hub, mid-span and tip based on two turbulence models (positive incidence angle case).

the stator-rotor interaction fundamentally changes the coolant jet/main flow interaction on the pressure surface, while the suction surface is relatively unaffected. The present calculation being 

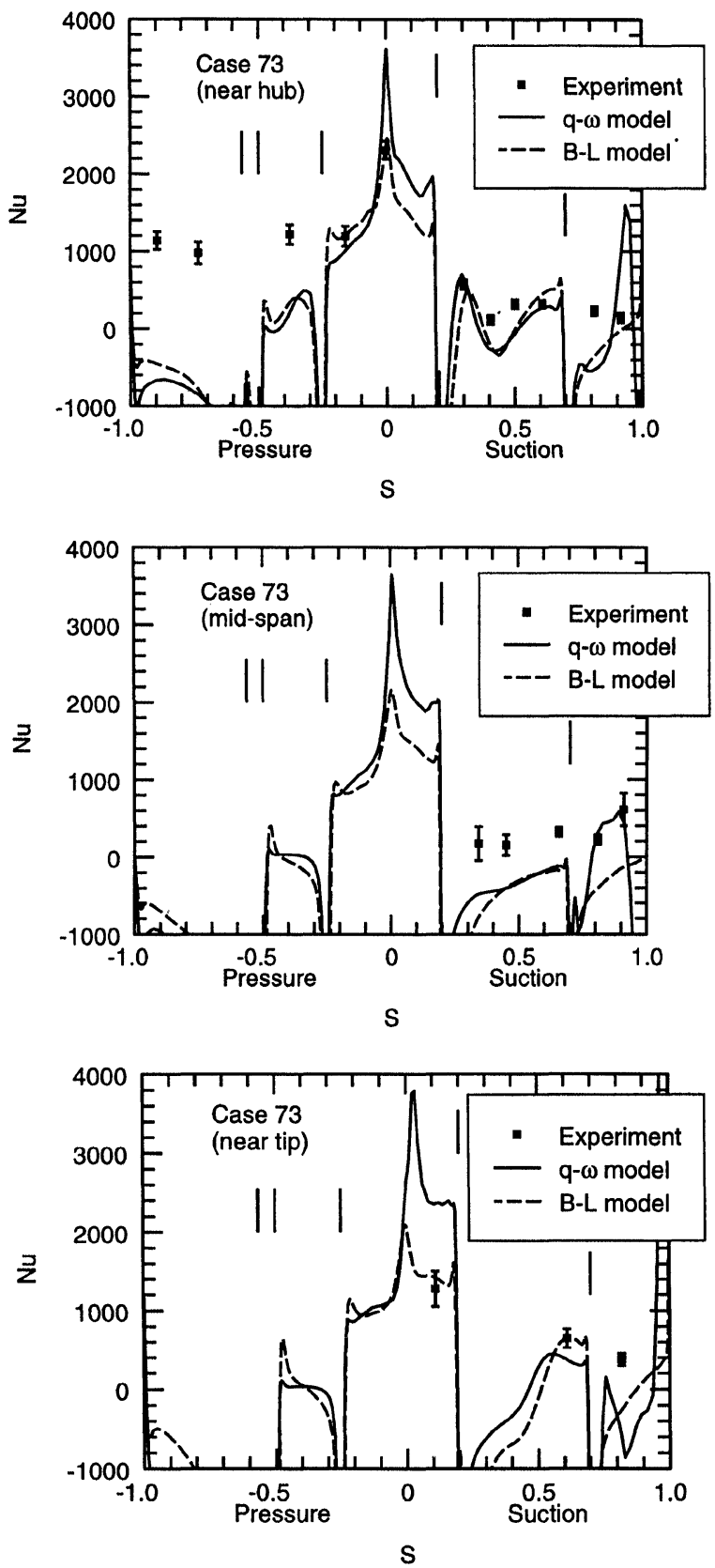

FIGURE 8 Comparison of Nusselt number on the blade surface for case 73 near hub, mid-span and tip based on two turbulence models (lower speed and pressure ratio).

steady-state does not model this unsteadiness. In the experimental tests, however, the rotor blades interact with the shock, wakes and the potential field of the upstream nozzle guide vanes resulting in a highly unsteady flow structure (Abhari et al., 1992). Another possible cause of this discrepancy can be the result of uncertainty in the values of (a) the blowing parameter and coolant temperature which were estimated using the one-dimensional compressible flow through the hole-pipe, and (b) the relative flow angle at inlet to the rotor which was estimated from a through-flow streamline curvature calculation, in the absence of experimental measurements. Also, the gas constant and specific heat ratios for the mainstream and coolant flow are different in the experiment owing to the use of different gas mixtures but the code assumes the same gas for both the main and coolant flows. Moreover, values of the discharge coefficients for the film-cooling holes were estimated, not measured. The blade surface was assumed to be isothermal while the experiment had $12-20 \%$ blade surface temperature variation. Finally, it is possible that the turbulent mixing on the low Mach number pressure surface is under-predicted by both turbulence models. While the results in Figs. 6-8 are based on a uniform coolant velocity and temperature distribution at the hole exits, specifying a polynomial distribution, like that in Garg and Gaugler (1997b), at the exit of the double-row of holes on the pressure surface, does not improve the comparison by more than $5 \%$ using the $\mathrm{B}-\mathrm{L}$ model (Garg and Abhari, 1997).

Figure 9 shows Nusselt number contours at increments of 200 over the entire blade surface for the three cases and both turbulence models. Comparing the results for the $q-\omega$ and $\mathrm{B}-\mathrm{L}$ models for each case, we find that while the Nusselt number values on the pressure surface are nearly similar, those on the suction surface have large differences in the leading edge region, hub and tip regions, and near the trailing edge. The $q-\omega$ model results in much higher heat loads than the $\mathrm{B}-\mathrm{L}$ model in these regions on the suction surface. Due to no film cooling over the leading edge portion, this part of the blade has a high Nusselt number for both models, being exposed to the hot stream for all the cases. Downstream of the first and subsequent rows of cooling holes on both the pressure 

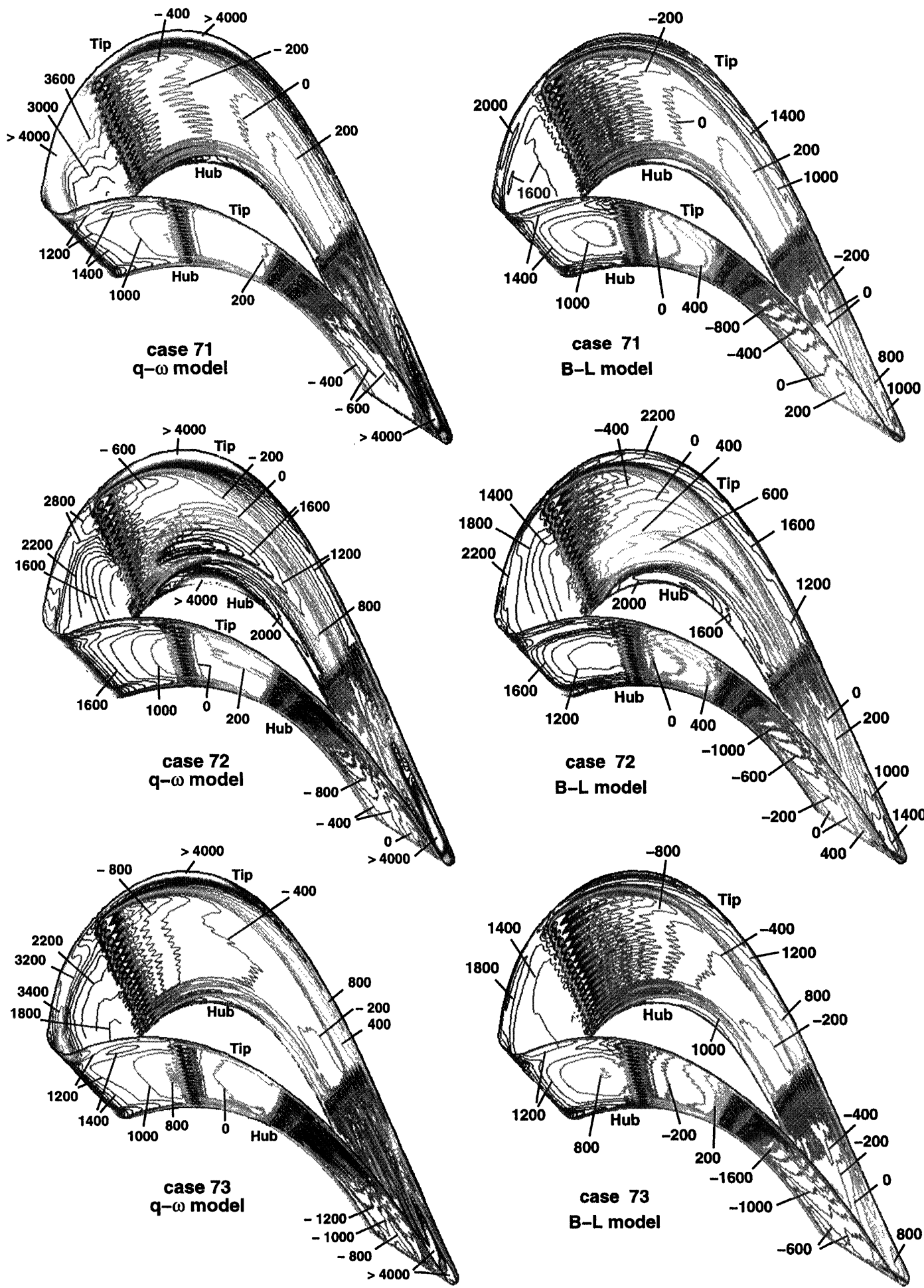

FIGURE 9 Nusselt number contours on the ACE rotor for various cases and two turbulence models. 
and suction surfaces, the effect of film cooling is clearly evident as streaks of lower heat load and generally lower Nusselt number values. For the offdesign case \#72, the blade suction surface upstream of the second row of holes has higher Nusselt number values than the other two cases. On the other hand, case \#73 has lower $N u$ values than all the other cases over almost the entire blade surface, and is thus the best-cooled case studied. It may also be observed that the Nusselt number is fairly high in the thick boundary layers on the suction surface near both the hub and the tip. From this figure, we observe that the Nusselt number is a strong function of the streamwise as well as the spanwise location, especially in the vicinity of film cooling holes.

\section{CONCLUSIONS}

A comparison of blade surface heat transfer between a fully three-dimensional Navier-Stokes code with Coakley's $q-\omega$ and Baldwin-Lomax turbulence models, and the experimental data obtained on a transonic rotating rotor blade with film cooling is presented. Both models provide a reasonably good prediction of the heat transfer on the suction surface of the film-cooled rotor blade when compared to the experimental data. At the leading edge, the Baldwin-Lomax model yields a much better comparison with the experimental value of Nusselt number than the $q-\omega$ model. On the pressure surface, however, both models underpredict the surface heat transfer. Reasons for differences on the pressure surface are cited; most plausible one seems to be the presence of unsteady effects due to stator-rotor interaction in the experiments which are neglected in the present computations. Overall, the Baldwin-Lomax model seems to provide a better comparison with the experimental data than the $q-\omega$ model, and the former requires at least $40 \%$ less computer time as well as storage. However, a lack of sufficient experimental data on a film-cooled rotating blade restricts us from drawing a definite conclusion regarding the choice of a turbulence model in such a case.

\section{NOMENCLATURE}

$B_{\mathrm{p}} \quad$ blowing parameter

$$
\left[=\left(\rho_{\mathrm{c}} V_{\mathrm{c}}\right) /\left\{\rho_{\mathrm{o}}\left(R T_{\mathrm{o}}\right)^{1 / 2}\right\}\right]
$$

$c_{\mathrm{a}} \quad$ axial chord of the blade

$C_{\mathrm{D}}$ discharge coefficient for the hole

$C_{v} \quad$ specific heat at constant volume

$d$ coolant hole diameter

$e \quad$ total energy

$J \quad$ Jacobian of the coordinate transformation

$k \quad$ turbulence kinetic energy

$k_{\mathrm{w}} \quad$ gas thermal conductivity at the blade temperature

$l \quad$ turbulence length scale

$M \quad$ Mach number

$\mathrm{Nu} \quad$ Nusselt number based on $c_{\mathrm{a}},\left(T_{\mathrm{o}, \mathrm{rel}}-T_{\mathrm{w}}\right)$ and $k_{\mathrm{w}}$

$p \quad$ pressure

Pr Prandtl number

$q \quad$ square root of turbulence kinetic energy

$r \quad$ radial coordinate

$R \quad$ gas constant

$R e \quad$ Reynolds number

$s \quad$ distance from the leading edge along the pressure or suction surface

$S=s / s_{\mathrm{m}}$ on suction surface, and $=-s / s_{\mathrm{m}}$ on pressure surface

$T$ temperature

$T u \quad$ turbulence intensity

$u, v, w$ absolute velocity components in the Cartesian coordinate system

$U, V, W$ contravariant velocity components

$V_{\mathrm{c}} \quad$ average coolant velocity at the hole exit

$(x, y, z)$ Cartesian coordinate system with origin at the geometric stagnation point, and $z$ coordinate along the span

$y^{+} \quad$ distance in wall coordinates off the blade surface 
$z^{+} \quad$ distance in wall coordinates off the hub or off the shroud

$\varepsilon \quad$ turbulence dissipation rate

$\gamma \quad$ ratio of specific heats

$\mu \quad$ viscosity

$\nu \quad$ kinematic viscosity

$\Omega \quad$ rotational speed of the blade

$\rho \quad$ density

$\omega \quad$ specific turbulence dissipation rate $(=\varepsilon / k)$

$(\xi, \eta, \zeta)$ curvilinear coordinate system with $\xi$ wrapping around the blade, $\eta$ running blade-to-blade, and $\zeta$ running spanwise

\section{Subscripts}

c for coolant (average value)

ef effective value

ex value at exit of rotor

in value at inlet

$\ell \quad$ laminar

$\mathrm{m}$ maximum value

o stagnation value

rel value relative to the rotor

$\mathrm{T}$ turbulent value

w value at wall

,$i \quad$ derivative with respect to $i$-direction coordinate

\section{Superscript}

relative velocity

\section{Acknowledgements}

The support provided by Dr. Raymond Gaugler, Chief, Turbine Branch, and by Mr. John Rohde of the Subsonic Systems Office at the NASA Lewis Research Center is gratefully acknowledged. A part of this paper was presented as ASME Paper 97-GT-220; we acknowledge permission from ASME to publish it.

\section{References}

Abhari, R.S. (1991) An Experimental Study of the Unsteady Heat Transfer Process in a Film Cooled Fully Scaled Transonic Turbine Stage, Ph.D. Thesis, Massachusetts Institute of Technology.

Abhari, R.S. (1996) Impact of Rotor-Stator Interaction on Turbine Blade Film Cooling, Journal of Turbomachinery, 118 , $123-133$.

Abhari, R.S. and Epstein, A.H. (1994) An Experimental Study of Film Cooling in a Rotating Transonic Turbine, Journal of Turbomachinery, 116, 63-70.

Abhari, R.S., Guenette, G.R., Epstein, A.H. and Giles, M.B. (1992) Comparison of Time-Resolved Measurements and Numerical Calculations, Journal of Turbomachinery, 114, $818-827$.

Ameri, A.A. and Arnone, A. (1992) Navier-Stokes Turbine Heat Transfer Predictions using Two-Equation Turbulence Closures, AIAA Paper 92-3067.

Ameri, A.A. and Arnone, A. (1994) Prediction of Turbine Blade Passage Heat Transfer using a Zero and a Two-Equation Turbulence Model, ASME Paper 94-GT-122.

Arnone, A. (1994) Viscous Analysis of Three-Dimensional Rotor Flow Using a Multigrid Method, Journal of Turbomachinery, 116, 435-445.

Baldwin, B.S. and Lomax, H. (1978) Thin-Layer Approximation and Algebraic Model for Separated Turbulent Flows, AIAA Paper 78-257.

Boyle, R.J. and Giel, P. (1992) Three-Dimensional Navier Stokes Heat Transfer Predictions for Turbine Blade Rows, AIAA Paper 92-3068.

Brandt, A. (1979) Multi-Level Adaptive Computations in Fluid Dynamics, AIAA Paper 79-1455.

Choi, D. (1993) A Navier-Stokes Analysis of Film Cooling in a Turbine Blade, AIAA Paper 93-0158.

Coakley, T.J. (1983) Turbulence Modeling Methods for the Compressible Navier-Stokes Equations, AIAA Paper 83-1693.

Crawford, M.E., Kays, W.M. and Moffat, R.J. (1980) Full Coverage Film Cooling on Flat, Isothermal Surfaces: A Summary Report on Data and Predictions, NASA CR 3219.

Dring, R.P., Blair, M.F. and Joslyn, H.D. (1980) An Experimental Investigation of Film Cooling on a Turbine Rotor Blade, Journal of Engineering for Power, 102, 81-87.

Garg, V.K. (1997) Adiabatic Effectiveness and Heat Transfer Coefficient on a Film-Cooled Rotating Blade, Numerical Heat Transfer, 32, Part A, 811-830.

Garg, V.K. and Abhari, R.S. (1997) Comparison of Predicted and Experimental Nusselt Number for a Film-Cooled Rotating Blade, International Journal of Heat and Fluid Flow, 18, $452-460$.

Garg, V.K. and Ameri, A.A. (1997) Comparison of TwoEquation Turbulence Models for Prediction of Heat Transfer on Film-Cooled Turbine Blades, Numerical Heat Transfer, 32, Part A, 347-371.

Garg, V.K. and Gaugler, R.E. (1993) Heat Transfer in FilmCooled Turbine Blades, ASME Paper 93-GT-81.

Garg, V.K. and Gaugler, R.E. (1994) Prediction of Film Cooling on Gas Turbine Airfoils, ASME Paper 94-GT-16.

Garg, V.K. and Gaugler, R.E. (1996) Leading-Edge FilmCooling Effects on Turbine Blade Heat Transfer, Numerical Heat Transfer, 30, Part A, 165-187.

Garg, V.K. and Gaugler, R.E. (1997a) Effect of Coolant Temperature and Mass Flow on Film Cooling of Turbine 
Blades, International Journal of Heat and Mass Transfer, 40, 435-445.

Garg, V.K. and Gaugler, R.E. (1997b) Effect of Velocity and Temperature Distribution at the Hole Exit on Film Cooling of Turbine Blades, Journal of Turbomachinery, 119, 343-351.

Goldstein, R.J. (1971) Film Cooling, in Advances in Heat Transfer, Eds. T.F. Irvine, Jr. and J.P. Hartnett, Vol. 7, pp. 321-379, Academic Press, New York.

Hall, E.J., Topp, D.A. and Delaney, R.A. (1994) Aerodynamic/ Heat Transfer Analysis of Discrete Site Film-Cooled Turbine Airfoils, AIAA Paper 94-3070.

Jameson, A. (1983) Transonic Flow Calculations, MAE Report 1651, MAE Department, Princeton University.

Jameson, A., Schmidt, W. and Turkel, E. (1981) Numerical Solutions of the Euler Equations by Finite Volume Methods Using Runge-Kutta Time-Stepping Schemes, AIAA Paper 81-1259.
Martinelli, L. (1987) Calculations of Viscous Flows With a Multigrid Method, Ph.D. Thesis, Princeton University.

Menter, F.R. (1993) Zonal Two Equation $k-\omega$ Turbulence Models for Aerodynamic Flows, AIAA Paper 93-2906.

Schlichting, H. (1979) Boundary Layer Theory, 7th Ed., McGraw-Hill, New York, p. 328

Schönung, B. and Rodi, W. (1987) Prediction of Film Cooling by a Row of Holes with a Two-Dimensional Boundary-Layer Procedure, Journal of Turbomachinery, 109, 579-587.

Tafti, D.K. and Yavuzkurt, S. (1990) Prediction of Heat Transfer Characteristics for Discrete Hole Film Cooling for Turbine Blade Applications, Journal of Turbomachinery, 112, 504-511.

Takeishi, K., Aoki, S., Sato, T. and Tsukagoshi, K. (1991) Film Cooling on a Gas Turbine Rotor Blade, ASME Paper 91-GT291. 


\section{ait \\ ENERGY MATERIALS}

M A N E Y publishing

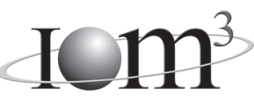

\section{Materials Science \& Engineering for Energy Systems}

Maney Publishing on behalf of the Institute of Materials, Minerals and Mining

The Institute of Materials, Minerals \& Mining

Economic and environmental factors are creating ever greater pressures for the efficient generation, transmission and use of energy. Materials developments are crucial to progress in all these areas: to innovation in design; to extending lifetime and maintenance intervals; and to successful operation in more demanding environments. Drawing together the broad community with interests in these areas, Energy Materials addresses materials needs in future energy generation, transmission, utilisation, conservation and storage. The journal covers thermal generation and gas turbines; renewable power (wind, wave, tidal, hydro, solar and geothermal); fuel cells (low and high temperature); materials issues relevant to biomass and biotechnology; nuclear power generation (fission and fusion); hydrogen generation and storage in the context of the 'hydrogen economy'; and the transmission and storage of the energy produced.

As well as publishing high-quality peer-reviewed research, Energy Materials promotes discussion of issues common to all sectors, through commissioned reviews and commentaries. The journal includes coverage of energy economics and policy, and broader social issues, since the political and legislative context influence research and investment decisions.

\section{CALL FOR PAPERS}

Contributions to the journal should be submitted online at http://ema.edmgr.com

To view the Notes for Contributors please visit: www.maney.co.uk/journals/notes/ema

Upon publication in 2006, this journal will be available via the Ingenta Connect journals service. To view free sample content online visit: www.ingentaconnect.com/content/maney

For further information please contact:

Maney Publishing UK

Tel: +44 (0)113 2497481 Fax: +44 (0)1132486983 Email: subscriptions@maney.co.uk

or

Maney Publishing North America

Tel (toll free): 8662975154 Fax: 6173546875 Email: maney@maneyusa.com

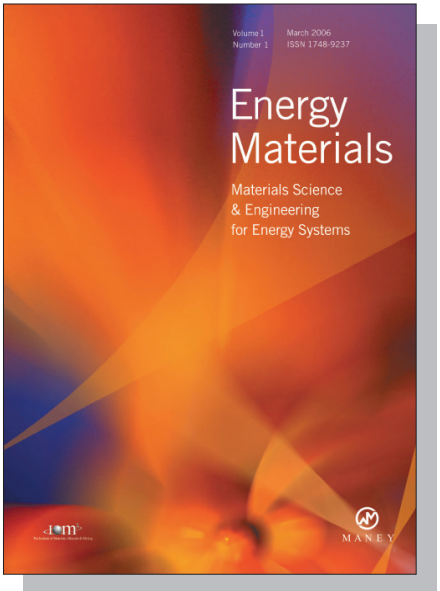

EDITORS

Dr Fujio Abe

NIMS, Japan

Dr John Hald, IPL-MPT, Technical University of Denmark, Denmark

Dr R Viswanathan, EPRI, USA

\section{SUBSCRIPTION INFORMATION}

Volume 1 (2006), 4 issues per year

Print ISSN: 1748-9237 Online ISSN: 1748-9245

Individual rate: $£ 76.00 / U S \$ 141.00$

Institutional rate: $£ 235.00 /$ US $\$ 435.00$

Online-only institutional rate: $£ 199.00 / U S \$ 367.00$

For special $\mathrm{IOM}^{3}$ member rates please email

subscriptions@maney.co.uk

\section{For further information or to subscribe online please visit www.maney.co.uk}



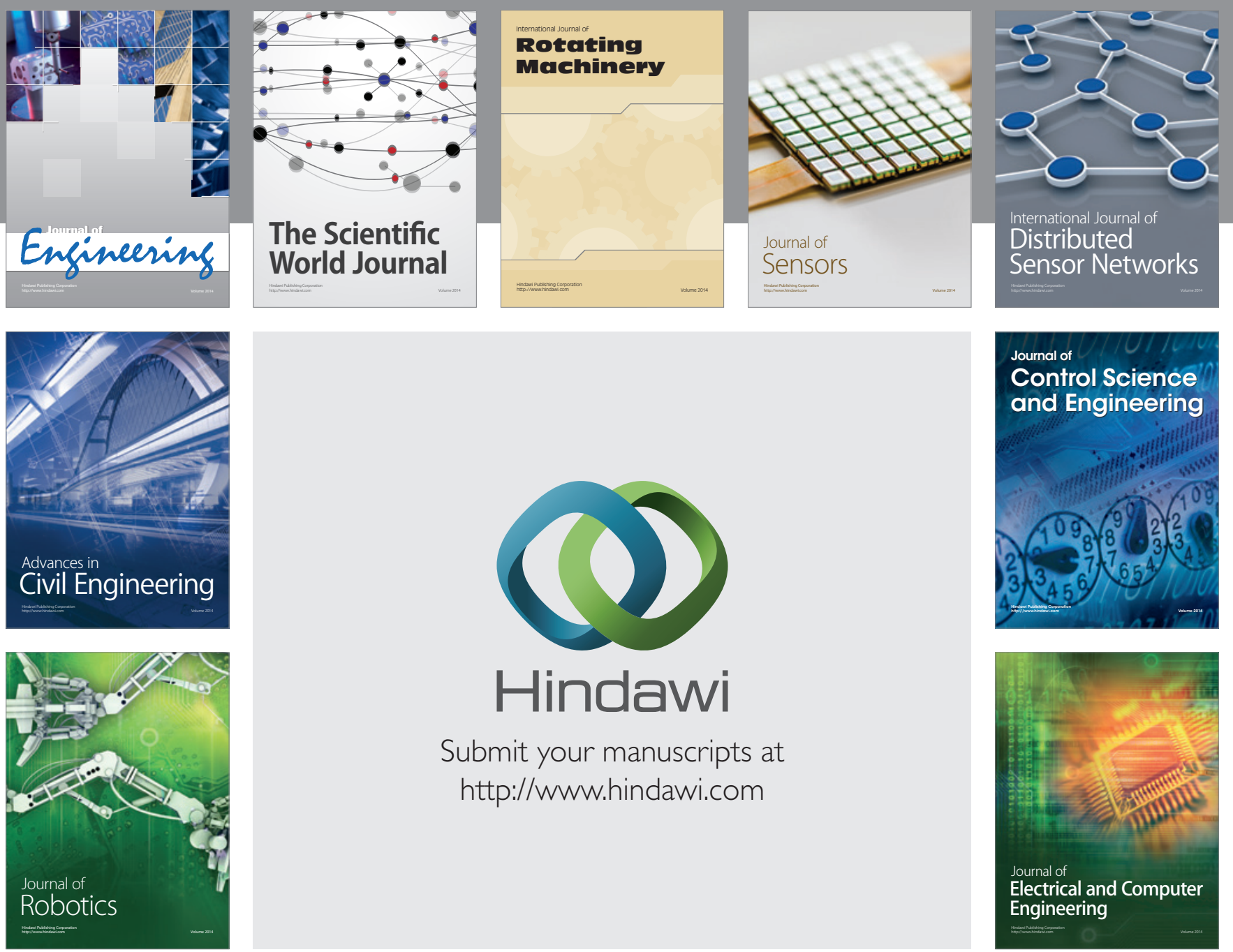

Submit your manuscripts at

http://www.hindawi.com
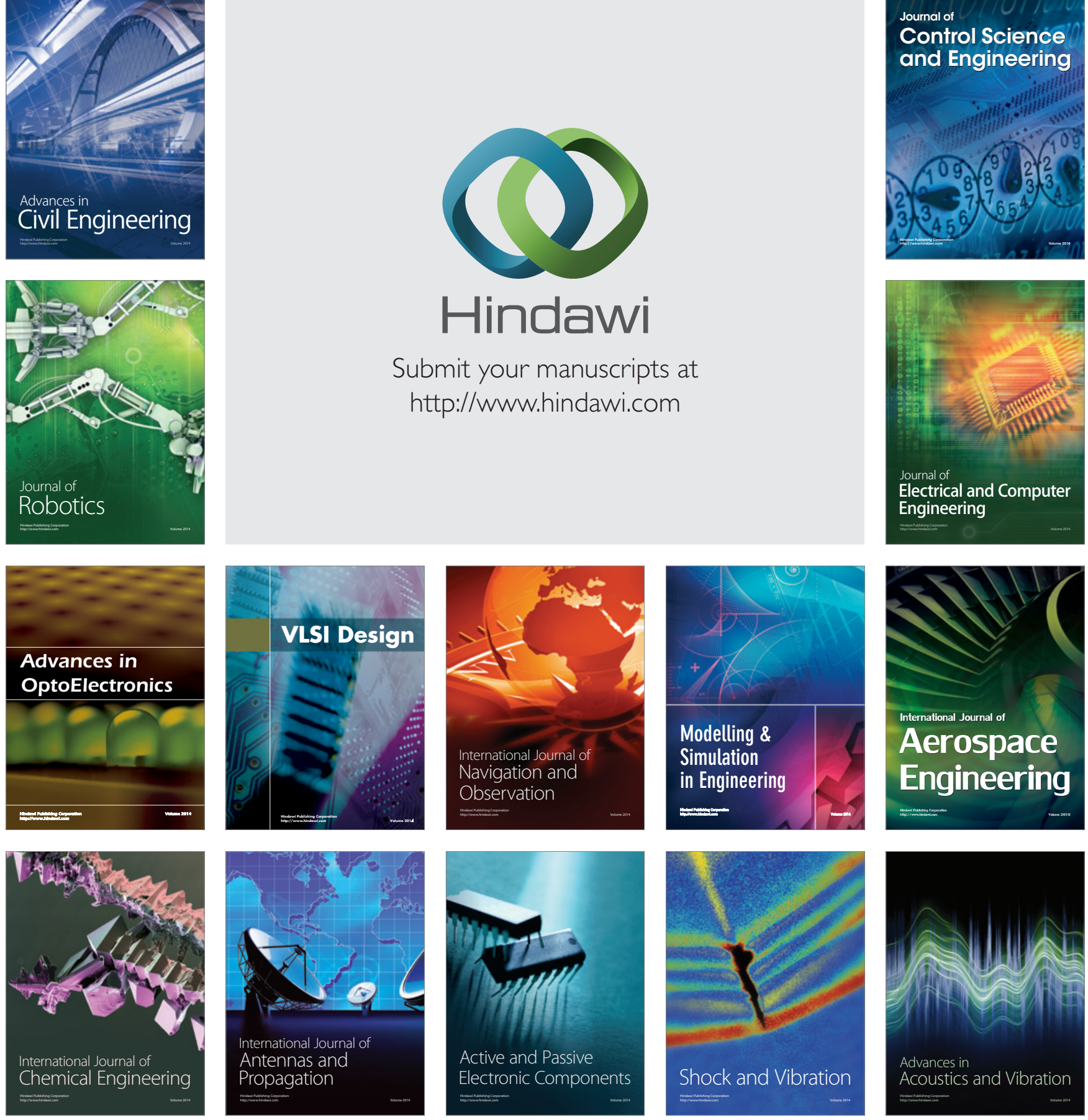